\title{
Predictors of Willingness of Participate in HIV Vaccine Trials among African Americans
}

\author{
Mindy Ma1, Toni Young A², Marcus Durham³ ${ }^{3}$, Jeffrey L Kibler ${ }^{1}$, Zaneta Gaul ${ }^{3,4}$, Sherri Pals ${ }^{3}$ and Madeline Y Sutton ${ }^{3 *}$ \\ ${ }^{1}$ Nova Southeastern University, Fort Lauderdale, FL, USA \\ ${ }^{2}$ Community Education Group, Washington, DC, USA \\ ${ }^{3}$ Division of HIVIAIDS Prevention, Centers for Disease Control and Prevention, Atlanta, GA, USA \\ ${ }^{4}$ ICF International, Atlanta, GA, USA
}

\begin{abstract}
African Americans in the United States (U.S.) are disproportionately affected by HIV. Developing an HIV vaccine is an important part of the HIV prevention and treatment toolkit and may help contribute to ending the HIV epidemic. To date, HIV vaccine trials have not engaged representative numbers of African Americans. We evaluated the willingness of African Americans to participate in HIV vaccine trials and identified correlates of willingness to participate (WTP) by surveying African Americans at low- and high-risk of HIV infection in a multi-site, cross-sectional study. We enrolled 1,452 participants; $59 \%$ heterosexual women; $21 \%$ heterosexual men; $20 \%$ men who have sex with men (MSM). Over half of participants (58\%) expressed some level of WTP in HIV vaccine trials. Multivariable analyses revealed several variables were positively related to WTP: HIV risk behavior, knowing someone with HIVIAIDS, social support for trial participation, high perception of risk, perceived protection if in a trial, altruism, and greater tolerance for the ambiguous nature of trials $(p<0.01)$. Emphasis on contextual factors related to personal HIV experiences, including knowledge of someone with HIV, and community support for research, may provide effective strategies for engaging African Americans in future HIV vaccine trials
\end{abstract}

Keywords: HIV; Vaccine; Clinical trials; African Americans; Willingness; Participation

\section{Introduction}

Substantial racial/ethnic disparities in human immunodeficiency virus (HIV) infection exist in the United States (U.S.), and African Americans are disproportionately affected by HIV infection. As such, African Americans are important partners for HIV prevention research if we are to effectively reduce the burden of HIV in highly affected communities [1]. The National Institutes of Health (NIH) Revitalization Act established guidelines for the inclusion of racial/ethnic minorities in all NIH-supported human subjects research unless a compelling rationale is provided for their exclusion [2]. Yet, achieving adequate representation of minority and marginalized groups in clinical trials has sometimes been challenging and has resulted in ambiguous efficacy results [3]. For example, the first phase-III efficacy trial of an HIV vaccine, AIDSVAX $B / \mathrm{B}^{1}$, indicated the vaccine was not efficacious for preventing HIV infection [4,5]. However, the protective efficacy of AIDSVAX B/B was initially reported to be $66.8 \%$ among black, Asian, and mixed-race participants; and $78.3 \%$ among African Americans alone $[4,5]$. Because the majority of AIDSVAX trial participants were white $(86 \%)$ and male $(94 \%)$, the trial lacked adequate statistical power to address pertinent questions regarding vaccine efficacy, immunologic responses, and behavioral risk among racial/ethnic subgroups and women $[4,5]$. The recent RV-144 HIV vaccine regimen conducted in Thailand had a modest efficacy of $31 \%$ [6], but the sample was not designed to address any racial/ethnic differences. However, the RV144 trial has generated new enthusiasm for HIV vaccine researchers working with broadly neutralizing antibodies capable of neutralizing different HIV strains $[7,8]$.

${ }^{1}$ AIDSVAX is an experimental preventive HIV vaccine that is made up of a synthetic copy of the surface protein of HIV called gp120. Because AIDSVAX is made up of synthetic or genetically engineered materials that lack all the elements required for infection, it cannot cause HIV infection. The vaccine that was tested in North America and Europe - AIDSVAX B/B - was designed to protect against subtype B which is the HIV strain prevalent in those areas as well as Central America, South America, Australia and New Zealand.
Numerous barriers have been suggested that may preclude the participation of African Americans in clinical trials and human immunodeficiency virus (HIV) prevention research. These barriers have been categorized into four broad categories: 1) characteristics of potential participants, 2) health care system issues, 3) knowledge, perceptions, and attitudes toward HIV and research, and 4) personal and temporal factors related to clinical trial participation [9-16]. Barriers within these categories include low perceived risk and education, limited access to and utilization of health care, racial disparities in service delivery and location (e.g., hospital versus community clinic), language and cultural barriers, distrust of the medical establishment, lack of knowledge about clinical trials, and lack of incentive for research participation [9,17-20].

Although knowledge regarding clinical trials has not been shown to be positively related to willingness to participate (WTP) $[14,21,22]$, educating individuals about the nature, purpose, and procedures of medical research is ethically essential and likely related to the successful recruitment of HIV clinical trial participants [23,24]. A lack of knowledge about HIV clinical trials has been documented in multiple communities $[25,26]$, indicating the need to provide information, dispel misinformation, and to build trust among those communities targeted for trials. Increased understanding of the impact of trial-

*Corresponding author: Madeline $\mathrm{Y}$ Sutton, MD, MPH, Centers for Disease Control and Prevention, National Center for HIV, STD, and TB Prevention, Division of HIVIAIDS Prevention, 1600 Clifton Road, MS E-45, USA, Tel: 4046391814 E-mail: zxa3@cdc.gov

Received August 04, 2014; Accepted September 27, 2014; Published October 10,2014

Citation: Ma M, Toni Young A, Durham M, Kibler JL, Gaul Z, et al. (2014) Predictors of Willingness of Participate in HIV Vaccine Trials among African Americans. J AIDS Clin Res 5: 361. doi:10.4172/2155-6113.1000361

Copyright: (c) 2014 Ma M, et al. This is an open-access article distributed unde the terms of the Creative Commons Attribution License, which permits unrestricted use, distribution, and reproduction in any medium, provided the original author and source are credited. 
related information on WTP among African Americans will inform health education approaches tailored for HIV prevention trials.

Distrust of the medical establishment by African Americans has been ascribed in part to racist attitudes, theories, and practices of physicians in the early 1800s [27], and to the United States Public Health Service funded Tuskegee Study of Untreated Syphilis in the Negro Male [28], which has come to symbolize ethical misconduct in clinical research $[28,29]$. The Tuskegee Study, widely criticized for providing inadequate informed consent and medical treatment, is perhaps the most frequently cited factor for distrust of the medical establishment among African Americans, especially those in the southeastern United States [27,29-32]. In the context of HIV, genocidal conspiracy beliefs have been observed among moderate segments of the African American communities [33,34], and has been cited as a major barrier to HIV prevention among these communities [30]. While there is substantial literature suggesting that historical factors such as slavery and the Tuskegee Study may inhibit the participation of African Americans in clinical trials, other personal and temporally relevant factors may also be related to clinical trial participation. For example, altruism, perceived and actual risk of HIV infection, knowing someone who is HIV-infected or who has AIDS, the desire to protect oneself from HIV infection, perceived normative support for trial participation, and tolerance for the ambiguous nature of clinical trial participation (e.g., blinding, unknown efficacy, potential for vaccine-induced seropositivity) have been shown to be related to WTP in clinical trials [12,25,35-38]. Evaluating the relative contribution of negative historic events and distrust to WTP in trials, as well as the temporally relevant factors in the context of HIV, may provide a more comprehensive understanding of WTP among African Americans that can inform strategies for achieving diversity in future trials, improve the generalizability of results, and benefit the public health of African American communities. Although advances have been made in the evaluation of barriers to WTP in clinical trials, most studies have focused on a limited set of predictors. The objective of the present study was to evaluate the willingness of African Americans to participate in phase II HIV vaccine trials and to identify correlates of willingness to participate (WTP) among African Americans using an expanded group of predictors.

\section{Methods}

\section{Participants}

African American men and women living in three cities: 1-Jackson, Mississippi, 2-Washington, District of Columbia (DC), and 3-Oakland, California, were enrolled from November 2005 through July 2006 and queried about issues related to willingness to participate in HIV vaccine trials. Background demographic and social data for the 3 recruitment cities are shown in Table 1 . Of note, each location had between 28\%-79\% African American populations and HIV prevalence rates of between 268 - 559 persons living with diagnosed HIV infection per 100,000 population (Table 1). Participants were recruited through convenience sampling at community events, beauty salons, and barber shops, block parties, bars, public parks, service organization venues, and community-based clinics across all 3 sites. Because the goal of the study was to evaluate the willingness of eligible African American participants to enroll in HIV vaccine trials, vaccine trial eligibility criteria were used to screen individuals for the study. Individuals were eligible if they self-identified as black or African American, or multiracial with black or African American heritage, and 18-70 years of age. Persons were also eligible if they were residents of one of the three study catchment areas, had not previously participated in a HIV vaccine trial, were HIV-seronegative and willing to be tested for HIV

\begin{tabular}{|l|c|c|c|}
\hline Characteristic & Jackson, MS & Washington, DC & Oakland, CA \\
\hline Total population & 173,514 & 601,723 & 390,724 \\
\hline African Americans & $79.4 \%$ & $50.7 \%$ & $28.0 \%$ \\
\hline Median household income & $\$ 30,219$ & $\$ 66,583$ & $\$ 48,196$ \\
\hline Employment & $60.7 \%$ & $69.0 \%$ & $66.8 \%$ \\
\hline Below poverty level & $26.8 \%$ & $13.9 \%$ & $19.5 \%$ \\
\hline Health insurance coverage & $78.4 \%$ & $94.1 \%$ & $83.1 \%$ \\
\hline HIV prevalence rate ${ }^{3}$ & 558.8 & 549.0 & 267.9 \\
\hline HIV vaccine trial experience & No & Yes & No \\
\hline
\end{tabular}

${ }^{1}$ Centers for Disease Control and Prevention. HIV Surveillance Report, 2011; vol. 23. http://www.cdc.gov/hiv/topics/surveillance/resources/reports/. Published February 2013.Accessed August 27, 2014.

${ }^{2}$ United States Census 2010. 2010 Census Interactive Population Search. http:// www.census.gov/2010census/popmap/ipmtext.php?fl=28. Accessed August 27, 2014.

${ }^{3}$ Persons living with diagnosed HIV infection, year-end 2010. Rates are per 100,000 population.

${ }^{4}$ ClinicalTrials.gov. http://clinicaltrials.gov/ct2/help/how-use-search-results. Accessed August 27, 2014.

Table 1: Demographic and social characteristics ${ }^{1,2}$ of the 3 U.S. cities from which persons were enrolled for African Americans' willingness to participate in HIV vaccine trials study.

antibodies, and had not been diagnosed with cancer, active liver disease or illnesses requiring immunotherapy such as interferon or steroids.

Study instruments were administered on-site using AudioComputer-Assisted Self-Interview (ACASI) software (NOVA Research: Questionnaire Development System version 2.1; NOVA, 1998). After individuals were determined to be eligible for the study, informed consent was obtained, and participants were oriented to the computerized interview. Participants completed a practice ACASI and addressed questions with study staff prior to initiating the survey. Staff members were available to answer questions during the interview. The ACASI included a section on WTP and predictors that are described in detail below. Institutional Review Boards at the Centers for Disease Control and Prevention, Jackson State University (Mississippi), the Whitman Walker Clinic (Washington, DC), and Independent Review Consulting, Inc (Oakland, CA) reviewed and approved this study protocol.

\section{Instruments}

Willingness to participate in HIV vaccine trials: To assess the influence of trial-related information on WTP in HIV vaccine trials, a computer-administered informed consent-like process presented information using a stepwise approach. Low risk and high risk among participants is defined below. Low-risk participants were presented information about phase-I HIV vaccine trials(i.e., phase-I trials are the first time a vaccine is given to people, are conducted to determine safety, usually involve about 100 people, require 12-18 months of followup). Following the presentation, participants were asked about their WTP in phase-I trials. Similarly, low- and high-risk individuals were presented information about phase-II trials (i.e., if a vaccine appears to be safe in phase-I trials, phase-II trials are conducted to learn more about safety and protective responses in the body. Hundreds of people are needed for phase II trials which can last 2-3 years) [39]. After this, WTP was again assessed. Finally, high-risk individuals were presented information about phase-III trials (i.e., if phase-II trials indicate that a vaccine is safe and causes the body to react in a way that might protect against infection, then phase-III trials are conducted. Phase-III trials test to see if a vaccine protects people from HIV. Thousands of people at high risk for HIV are needed for phase-III trials, which can last from 3-5 years); [39] subsequently, WTP was again assessed. Because phase-II trials include both low and high risk participants, willingness 
to participate in phase-II trials was the outcome variable in the WTP analyses for the current study.

HIV risk behavior: Participants were asked with how many HIV-infected, HIV-uninfected, and HIV-unknown serostatus men and women they had sex with in the three months prior to study enrollment, along with questions on frequency of sex and condom use. Participants were also asked if they had sex with anyone known to have had a sexually transmitted infection (STI) or injected drugs; had a sexually transmitted infection themselves; or exchanged sex for money, drugs, or shelter. Women were also asked if they recently had sex with a man who had been in prison. Participants also responded to questions on injected drug use and crack cocaine smoking. Participants were classified to be at low risk of HIV infection if they were in a mutually monogamous relationship with an HIV-uninfected partner during the past year or did not report any of the following: smoked crack, exchanged sex for money or drugs; had sex with more than two partners and reported infrequent condom use; had sex with another man (men only); had sex with a HIV-infected partner, injecting drug user, a partner with a recent sexually transmitted infection or who had recently been in prison (women only). Any participant reporting any of the preceding behaviors or circumstances were classified as high risk.

Sexual identity: Participants responded to a series of questions on sexual identity as well as gender of sex partners. Men were categorized as "men who have sex with men" (MSM) if they self-identified as homosexual, MSM, or reported having sex with another man in the past 3 months.

Access to medical care: Participants indicated the extent to which they had access to medical care by selecting one of the following: (a) I have all the medical care that I need, (b) I have good medical care but not all that I need, (c) My access to medical care is very limited, (d) I rarely get good medical care, and (e) I have no access to medical care.

Knowledge of clinical trials, HIV vaccine trials, and the tuskegee syphilis study: To assess knowledge of clinical trials generally and HIV vaccine trials, 17 questions were administered (True/False/Don't know) addressing the purpose of trials, informed consent, representation of African Americans in trials, HIV antibody testing requirements, risk of infection from study vaccine, and the need to practice safe sex if in a trial. Participants were also asked if they had ever heard of the Tuskegee Syphilis Study (Yes/No) and if so, seven additional questions were administered regarding specific knowledge about the study (True/ False/Don't know).

Multidimensional vaccine attitude inventory (MVAI): A subset of the MVAI (14 items) was used to measure four constructs previously shown to be related to WTP in HIV vaccine trials [36]. The constructs assessed include genocidal conspiracy beliefs ( 3 items, $\alpha=0.78$ ), perceived decreased risk of HIV infection (4 items, $\alpha=0.78$ ), altruism (3 items, $\alpha=0.72$ ), and Tolerance for the ambiguous nature of trials (4 items, $\alpha=0.78$ ). For all items, participants responded using a 5-point Likerttype scale.

Barriers to research participation questionnaire (BRPQ): A 17-item instrument developed by Kibler and Brisco [40] was used to measure five constructs that may be associated with WTP in HIV prevention trials [9]. The constructs assessed by the BRPQ include mistrust toward researchers' motives and government sponsorships of research, incentives for participation, role overload (perception of serving in multiple social or occupational roles), religious beliefs that may be inconsistent with participation in scientific research, and health beliefs that could affect sentiments toward research. Psychometric examination of the BRPQ has indicated support for the five factors through confirmatory factor analysis, as well as good three-week testretestreliability $(r=0.80)$ and marginal internal consistency $(\alpha=0.63)$ [40]. The BRPQ uses a five-point Likert type scale for responses.

Knowing someone with HIV/AIDS and social support for trial participation: Participants were asked if they knew anyone who was infected with HIV or who had AIDS (2 questions). Social support for trial participation was assessed by combining three 5-point Likert-type items addressing whether friends, family, and sexual partners would support their decision to participate in HIV vaccine trials $(\alpha=0.91)$.

Perceived risk of HIV infection: Perceived risk was assessed using three Likert-scale response questions:1-"How likely do you think it would be for you to become infected with HIV in the next 5 years?"; 2-“Do you believe that you are at low, medium, or high risk for becoming HIV infected?"; and 3-"My current sexual partner(s) place me at-risk of becoming infected with HIV." Responses to the questions were summed to derive an index score of perceived HIV risk.

\section{Data analyses}

Chi-square tests of independence for categorical variables and oneway analysis of variance for continuous variables were utilized to compare participants in three US cities on demographic variables. Because the dependent variable, WTP in HIV vaccine trials, is an ordered response variable, ordinal regression analyses were employed to assess the correlates of each independent variable to WTP in HIV vaccine trials. Initially, the bivariate relationships of the covariates to WTP in HIV vaccine trials were assessed by conducting separate ordinal regression analyses for each independent variable: HIV risk, sexual identity, study site, access to health care, knowledge about clinical trials, knowledge of HIV vaccine trials, awareness of the Tuskegee syphilis study, HIV/ AIDS genocidal conspiracy, mistrust, knowing someone with HIV/ AIDS, social network support for trial participation, perceptions of HIV risk, perceived protection in trial participation, altruism, incentive for trial participation, role overload, tolerance for ambiguity, religious beliefs precluding research participation, and health beliefs precluding research participation. Independent variables that were significantly related to WTP in the bivariate analyses $(\mathrm{p}<0.05)$ were retained for the multivariable analyses. Positive beta coefficients indicated a positive association with WTP, and negative beta coefficients indicated a negative association with WTP.

\section{Results}

Of 1,859 individuals screened for the study, 1,665 (89.6\%) were eligible to participate. Reasons for ineligibility included HIV infection (3.7\%); a health condition other than HIV that would result in ineligibility for an actual HIV vaccine trial (2.6\%); living outside of a study site catchment area (2.8\%); participation in a previous HIV vaccine trial (0.7\%); not being of black or African American descent (0.6\%); unwilling to test for HIV antibodies and thus not eligible to participate in an actual trial $(0.3 \%)$; and not meeting the age requirements for participation $(0.3 \%)$. Valid and complete ACASI records were obtained from $1,452(87.2 \%)$ of the 1,665 eligible individuals.

\section{Descriptive results}

Participant characteristics are summarized in Table 2. There were significant differences in age across the three study sites with participants in Oakland being the oldest and Jackson being the youngest $(p<0.01)$. Of note, most participants reported $\leq$ high school education, with those from Oakland being the least likely to have completed high 
Citation: Ma M, Toni Young A, Durham M, Kibler JL, Gaul Z, et al. (2014) Predictors of Willingness of Participate in HIV Vaccine Trials among African Americans. J AIDS Clin Res 5: 361. doi:10.4172/2155-6113.1000361

Page 4 of 7

school $(p<0.01)$. Approximately half of participants reported an income of $<\$ 10,000$ per year, with those from Oakland reporting lower income than participants from the other sites $(p<0.01)$. While the majority of the participants were single, more participants from Jackson reported being married $(p<0.01)$. Overall, self-reported HIV risk behavior was similar across sites. However, participants from Oakland were more likely to report smoking crack cocaine $(p<0.01)$, DC participants reported a higher rate of having sex with partners who injected drugs $(p<0.05)$, and those from Jackson were more likely to report having had an STI $(p<0.05)$.

\section{Predictor variables}

Knowledge about clinical trials was fairly good; $76.6 \%$ of the questions about clinical trials were answered correctly (Table 3).

\begin{tabular}{|c|c|c|c|c|}
\hline \multirow[b]{2}{*}{ Variable } & \multicolumn{3}{|c|}{ Study Site } & \multirow[b]{2}{*}{$p^{\dagger}$} \\
\hline & $\begin{array}{c}\text { Jackson, MS } \\
(n=570)\end{array}$ & $\begin{array}{l}\text { Washington, DC } \\
\quad(n=543)\end{array}$ & $\begin{array}{c}\text { Oakland, CA } \\
(n=339)\end{array}$ & \\
\hline Mean Age (SD) & $30.2 \pm 10.1$ & $36.7 \pm 12.3$ & $40.7 \pm 11.6$ & $<0.01$ \\
\hline $\begin{array}{l}\text { Education } \\
\qquad \text { <igh school } \\
\text { High school } \\
\text { College graduate } \\
\text { Graduate School }\end{array}$ & $\begin{array}{c}16.1 \% \\
63.8 \% \\
16.3 \% \\
3.7 \%\end{array}$ & $\begin{array}{c}15.7 \% \\
74.6 \% \\
7.6 \% \\
2.2 \%\end{array}$ & $\begin{array}{c}27.8 \% \\
61.5 \% \\
9.5 \% \\
1.2 \%\end{array}$ & $<0.01$ \\
\hline \begin{tabular}{|} 
Marital Status \\
Single \\
Married \\
Divorced, Separated, \\
or Widowed
\end{tabular} & $\begin{array}{c}76.5 \% \\
14.4 \% \\
9.2 \%\end{array}$ & $\begin{array}{c}72.4 \% \\
9.2 \% \\
18.4 \%\end{array}$ & $\begin{array}{c}72.3 \% \\
9.7 \% \\
18.0 \%\end{array}$ & $<0.01$ \\
\hline $\begin{aligned} \text { Income } & \\
& <\$ 10,000 \\
& \$ 10,000-\$ 19,999 \\
& \$ 20,000-\$ 34,999 \\
& \$ 35,000-\$ 49,999 \\
& \geq \$ 50,000\end{aligned}$ & $\begin{array}{l}45.3 \% \\
19.6 \% \\
18.8 \% \\
10.0 \% \\
6.4 \%\end{array}$ & $\begin{array}{c}43.1 \% \\
13.6 \% \\
20.1 \% \\
13.6 \% \\
9.5 \%\end{array}$ & $\begin{array}{l}64.6 \% \\
18.6 \% \\
5.6 \% \\
7.1 \% \\
4.2 \%\end{array}$ & $<0.01$ \\
\hline Injected drugs & $3.2 \%$ & $5.7 \%$ & $5.3 \%$ & NS \\
\hline Smoked crack cocaine & $8.4 \%$ & $10.3 \%$ & $25.7 \%$ & $<0.01$ \\
\hline Sex partner had STI & $5.9 \%$ & $6.0 \%$ & $3.7 \%$ & NS \\
\hline Sex with IDU & $3.9 \%$ & $7.8 \%$ & $5.3 \%$ & $<0.05$ \\
\hline Had STI & $6.5 \%$ & $3.8 \%$ & $3.0 \%$ & $<0.05$ \\
\hline Exchanged sex for drugs or money & $8.4 \%$ & $12.3 \%$ & $9.8 \%$ & NS \\
\hline Sex partner recently in jail (women only) & $20.3 \%$ & $18.6 \%$ & $24.7 \%$ & NS \\
\hline
\end{tabular}

Note. STI - sexually transmitted infection; IDU - injecting drug user; NS - non-significant; SD-standard deviation; ${ }^{\dagger} X^{2}$ test of independence

Table 2: Demographic and HIV risk characteristics of African Americans enrolled from three U.S. cites. $(n=1,452)$.

\begin{tabular}{|c|c|c|}
\hline Variables & Statistics & Scale \\
\hline $\begin{array}{l}\text { Participant characteristic } \\
\text { HIV Risk } \\
\text { Low } \\
\text { High } \\
\text { Sexual Identity } \\
\text { Heterosexual men } \\
\text { Men who have sex with men } \\
\text { Heterosexual women }\end{array}$ & $\begin{array}{c}53.0 \% \\
47.0 \% \\
\\
21 \% \\
20 \% \\
59 \%\end{array}$ & $\begin{array}{l}\text { Percent of Participants } \\
\text { Percent of Participants }\end{array}$ \\
\hline $\begin{array}{l}\text { Healthcare system issue } \\
\text { Adequate healthcare access } \\
\text { Knowledge, perception, and attitude toward HIV and Research } \\
\text { Knowledge about clinical trials } \\
\text { Knowledge about HIV vaccine trials } \\
\text { Awareness of the Tuskegee Syphilis Study } \\
\text { HIVIAIDS genocidal conspiracy } \\
\text { Mistrust } \\
\text { Personal and temporal factors related to clinical trial participation } \\
\text { Know someone infected with HIVIAIDS } \\
\text { Social network support for trial participation } \\
\text { Perceptions of HIV Risk } \\
\text { perceived protection in trial participation } \\
\text { Altruism } \\
\text { Incentive for participation } \\
\text { Role overload (serving in multiple social or occupational roles) } \\
\text { Tolerance for ambiguity } \\
\text { Religious beliefs precluding research participation } \\
\text { Health beliefs precluding research participation }\end{array}$ & $\begin{array}{l}2.3 \pm 1.2^{\mathrm{a}} \\
76.6 \% \\
66.4 \% \\
41.4 \% \\
2.8 \pm 1.1^{\mathrm{a}} \\
3.1 \pm 0.8^{\mathrm{a}} \\
55.9 \% \\
3.2 \pm 0.5^{\mathrm{a}} \\
1.6 \pm 0.6^{\mathrm{a}} \\
2.7 \pm 0.8^{\mathrm{a}} \\
3.4 \pm 0.8^{\mathrm{a}} \\
3.1 \pm 0.4^{\mathrm{a}} \\
2.4 \pm 1.0^{\mathrm{a}} \\
3.1 \pm 0.8^{\mathrm{a}} \\
3.3 \pm 0.9^{\mathrm{a}} \\
2.0 \pm 0.7^{\mathrm{a}}\end{array}$ & $\begin{array}{c}\text { 1=Complete Access, } 5=\text { No Access } \\
\text { Percent Correct Responses } \\
\text { Percent Correct Responses } \\
\text { Percent of Participants } \\
1=\text { Strongly Disagree, } 5=\text { Strongly Agree } \\
1=\text { Strongly Disagree, } 5=\text { Strongly Agree } \\
\text { Percent of Participants } \\
1=\text { Strongly Disagree, } 5=\text { Strongly Agree } \\
1=\text { Low Risk, } 4=\text { High Risk } \\
1=\text { Strongly Disagree, } 5=\text { Strongly Agree } \\
1=\text { Strongly Disagree, } 5=\text { Strongly Agree } \\
1=\text { Strongly Disagree, } 5=\text { Strongly Agree } \\
1=\text { Strongly Disagree, } 5=\text { Strongly Agree } \\
1=\text { Strongly Disagree, } 5=\text { Strongly Agree } \\
1=\text { Strongly Disagree, } 5=\text { Strongly Agree } \\
1=\text { Strongly Disagree, } 5=\text { Strongly Agree }\end{array}$ \\
\hline
\end{tabular}

Note. $a=$ Mean \pm SD

Table 3: Summary scores of predictor variables for African Americans' willingness to participate in HIV vaccine trials enrolled from three U.S. cites. ( $n=1,452$ ). 


\begin{tabular}{|l|c|c|c|}
\hline Variables & $\boldsymbol{\beta}$ & $\begin{array}{c}\text { Standard } \\
\text { error }\end{array}$ & $\boldsymbol{p}$ value \\
\hline HIV Risk & .42 & .11 & $<0.01$ \\
\hline Adequate healthcare access & .12 & .05 & $<0.01$ \\
\hline Knowledge about HIV vaccine trials & .01 & .01 & .581 \\
\hline HIVIAIDS genocidal conspiracy & -.24 & .06 & $<0.01$ \\
\hline Mistrust & -.07 & .01 & $<0.01$ \\
\hline Know someone infected with HIV & .20 & .11 & .059 \\
\hline Social network support for trial participation & .58 & .12 & $<0.01$ \\
\hline Perception of HIV Risk & .20 & .09 & $<0.05$ \\
\hline Perceived protection in trial participation & .36 & .07 & $<0.01$ \\
\hline Altruism & 1.14 & .09 & $<0.01$ \\
\hline $\begin{array}{l}\text { Role overload(serving in multiple social or } \\
\text { occupational roles) }\end{array}$ & -.09 & .05 & .096 \\
\hline Tolerance for ambiguity & -.43 & .07 & $<0.01$ \\
\hline
\end{tabular}

\section{Discussion}

This study assessed the willingness of African American men and women at low and high risk of HIV infection to participate in HIV vaccine trials. This study adds to previous literature by evaluating a comprehensive set of correlates, including: 1) participant characteristics, 2) health care system issues, 3) knowledge, perceptions, and attitudes toward HIV and research, and 4) personal and temporal factors related to clinical trial participation. The results suggest all four domains contribute to WTP in vaccine trials among African Americans.

As others have indicated, high-risk participants reported greater WTP in vaccine trials $[9,41]$. Participants with less healthcare access also reported more WTP. These results are likely due to the perceived health benefit of trial participation. Consistent with the literature [9], historic distrust variables were generally related to WTP, with mistrust and the belief in HIV genocidal conspiracy providing independent negative associations with WTP. Among the four domains assessed, variables likely to be temporally and personally relevant to individuals in the context of HIV emerged as the stronger predictors of WTP. Altruism was the most prominent factor related to WTP, suggesting that helping one's community improve the health of its residents was the strongest motivator for trial participation. Social support for trial participation, perceived behavioral risk of HIV infection, perceptions of decreased risk if enrolled in a trial, and intolerance for the ambiguous nature of trials also showed strong association with WTP in Phase- II vaccine trials.

These findings indicate that, while there has previously been suspicion by some that African Americans might be used inappropriately in HIV-related research [42], such negative feelings were not as prominent among these study participants. Trial sponsors interested in achieving racial and ethnic diversity in future HIV vaccine research should incorporate strategies that appeal to altruistic motivations to help one's community, educate individuals as to their risk of HIV infection, mobilize the community to provide a supportive environment for vaccine trial participation, develop educational and consent processes that minimize the ambiguity associated with trial participation (blinding, unknown efficacy, potential for social harm, potential social reactions, HIV testing), and partner with HIV-infected individuals who may want to appeal to their friends and community to participate in HIV vaccine trials [13]. Popular opinion leaders, including public figures who are HIV infected and willing to disclose their status while they appeal to other African Americans to participate in HIV research and HIV vaccine trials might also help to increase ethnic diversity in future trials [13].

Our study had some notable limitations. While the sample size in this study far exceeded that of previous studies evaluating the willingness of African Americans to participate in HIV-related clinical trials, our non-probability sample precludes the generalization of these findings to other diverse African American communities. However, the lack of differences in WTP across study sites demonstrates the possibility that willingness may not vary by geographic location. Additionally, the evaluation of WTP in a hypothetical HIV vaccine trial may not accurately reflect actual enrollment in trials as pointed out by Buchbinder et al. [25]. However, WTP in hypothetical trials has been shown to be a strong predictor of enrollment in actual trials [21]. Also, our data were collected some years ago. However, more recent HIV vaccine WTP studies have similarly concluded that African Americans are willing to be engaged in this research, given appropriate cultural context $[13,41]$ and even community liaison programs [43].

Despite the limitations, a major advantage of this study was that 
Citation: Ma M, Toni Young A, Durham M, Kibler JL, Gaul Z, et al. (2014) Predictors of Willingness of Participate in HIV Vaccine Trials among African Americans. J AIDS Clin Res 5: 361. doi:10.4172/2155-6113.1000361

it evaluated participant characteristics, healthcare access, historic distrust variables, as well as those that may be more personally and temporally relevant to the individual in the context of HIV. Although not a significant predictor in our study, the Tuskegee Study legacy and distrust of researchers/medical establishment are important factors that cannot be ignored when planning and conducting HIV prevention research and programs in African American communities [33]. In addition to building trust, emphasis on temporally-relevant contextual factors related to personal HIV experiences, including knowledge of someone with HIV, and community support for vaccine trials, may provide an effective strategy for engaging African Americans in HIV vaccine trials and working toward reduced HIV-related disparities.

\section{Acknowledgements}

The authors thank the study participants for their willingness to participate in this study and the time they spent providing information to inform public health efforts for HIV prevention. Also, the authors are extremely grateful to Bradford Bartholow, K. Shakira Washington, Carla Dillard-Smith, Gloria Lockett, David Fluker, Lisa Fitzpatrick, Alan Greenberg, and Eleanor McLellan-Lemalfor their generous contributions of time, talent, and commitment to the Minority HIVIAIDS Research Initiative.

\section{References}

1. Centers for Disease Control and Prevention (2011) HIV Surveillance Report.

2. Freedman LS, Simon R, Foulkes MA, Friedman L, Geller NL, et al. (1995) Inclusion of women and minorities in clinical trials and the NIH Revitalization Act of 1993--the perspective of NIH clinical trialists. Control Clin Trials 16: 277 285

3. Hussain-Gambles M, Atkin K, Leese B (2004) Why ethnic minority groups are under-represented in clinical trials: a review of the literature. Health Soc Care Community 12 : 382-388.

4. Cohen J (2003) HIVIAIDS. Vaccine results lose significance under scrutiny Science 299: 1495

5. Cohen J (2003) Public health. AIDS vaccine trial produces disappointment and confusion. Science 299: 1290-1291.

6. Rerks-Ngarm S, Pitisuttithum P, Nitayaphan S, Kaewkungwal J, Chiu J, et al. (2009) Vaccination with ALVAC and AIDSVAX to prevent HIV-1 infection in Thailand. N Engl J Med 361: 2209-2220.

7. Fauci AS, Marston HD (2014) Ending AIDS--is an HIV vaccine necessary? N Engl J Med 370: 495-498.

8. Nageswara Rao A (2014) The Pursuit of a HIV Vaccine - Trials, Challenges and Strategies. J AIDS Clin Res 5: 298.

9. Ma M, Kibler JL, Vigil-Otero A, Sarpong D, Lally M, et al. (2013) Correlates of willingness to participate in microbicide research among African Americans. J Health Psychol 18: 65-74

10. DeFreitas D (2010) Race and HIV clinical trial participation. J Natl Med Assoc 102: 493-499.

11. Slomka J, Ratliff EA, McCurdy SA, Timpson S, Williams ML (2008) Decisions to participate in research: views of underserved minority drug users with or at risk for HIV. AIDS Care 20: 1224-1232.

12. Newman PA, Duan N, Roberts KJ, Seiden D, Rudy ET, et al. (2006) HIV vaccine trial participation among ethnic minority communities: barriers, motivators, and implications for recruitment. J Acquir Immune Defic Syndr 41: 210-217.

13. Frew PM, Archibald M, Diallo DD, Hou SI, Horton T, et al. (2010) An extended model of reasoned action to understand the influence of individual- and networklevel factors on African Americans' participation in HIV vaccine research. Prev Sci 11: 207-218

14. Priddy FH, Cheng AC, Salazar LF, Frew PM (2006) Racial and ethnic differences in knowledge and willingness to participate in HIV vaccine trials in an urban population in the Southeastern US. Int J STD AIDS 17: 99-102.

15. Sengupta S, Strauss RP, DeVellis R, Quinn SC, DeVellis B, et al. (2000) Factors affecting African-American participation in AIDS research. J Acquir Immune Defic Syndr 24: 275-284.

16. Moutsiakis DL, Chin PN (2007) Why blacks do not take part in HIV vaccine trials. J Natl Med Assoc 99: 254-257.
17. Shavers-Hornaday VL, Lynch CF, Burmeister LF, Torner JC (1997) Why are African Americans under-represented in medical research studies? Impediments to participation. Ethn Health 2: 31-45.

18. Shavers VL, Lynch CF, Burmeister LF (2001) Factors that influence AfricanAmericans' willingness to participate in medical research studies. Cancer 91 : 233-236.

19. King TE Jr, Wheeler MB (2004) Inequality in health care: unjust, inhumane, and unattended! Ann Intern Med 141: 815-817.

20. McCarthy CR (1994) Historical background of clinical trials involving women and minorities. Acad Med 69: 695-698.

21. Halpern SD, Metzger DS, Berlin JA, Ubel PA (2001) Who will enroll? Predicting participation in a phase II AIDS vaccine trial. J Acquir Immune Defic Syndr 27 281-288.

22. Dhalla S, Poole G, Singer J, Patrick DM, Wood E, et al. (2012) Cognitive factors and willingness to participate in an HIV vaccine trial among HIV-negative injection drug users. Psychol Health Med 17: 223-234.

23. Fisher CB (2010) Enhancing HIV vaccine trial consent preparedness among street drug users. J Empir Res Hum Res Ethics 5: 65-80.

24. Coletti AS, Heagerty P, Sheon AR, Gross M, Koblin BA, et al. (2003) Randomized, controlled evaluation of a prototype informed consent process for HIV vaccine efficacy trials. J Acquir Immune Defic Syndr 32: 161-169.

25. Buchbinder SP, Metch B, Holte SE, Scheer S, Coletti A, et al. (2004) Determinants of enrollment in a preventive HIV vaccine trial: hypothetical versus actual willingness and barriers to participation. J Acquir Immune Defic Syndr 36: 604-612.

26. Roberts KJ, Newman PA, Duan N, Rudy ET (2005) HIV vaccine knowledge and beliefs among communities at elevated risk: conspiracies, questions and confusion. J Natl Med Assoc 97: 1662-1671.

27. Gamble VN (1993) A legacy of distrust: African Americans and medical research. Am J Prev Med 9: 35-38.

28. Hastings Center (1992) Twenty years after: The legacy of the Tuskegee syphilis study. Hastings Center Report 22: 29.

29. Corbie-Smith G, Thomas SB, St George DM (2002) Distrust, race, and research. Arch Intern Med 162: 2458-2463.

30. Fullilove R (2004) The elephant in the room: AIDS conspiracies in the Black community. Focus 19: 1-5.

31. Katz RV, Kegeles SS, Green BL, Kressin NR, James SA, et al. (2003) The Tuskegee Legacy Project: history, preliminary scientific findings, and unanticipated societal benefits. Dent Clin North Am 47: 1-19.

32. White RM (2000) Unraveling the Tuskegee Study of Untreated Syphilis. Arch Intern Med 160: 585-598.

33. Russell SL, Katz RV, Wang MQ, Lee R, Green BL, et al. (2011) Belief in AIDS origin conspiracy theory and willingness to participate in biomedical research studies: findings in whites, blacks, and Hispanics in seven cities across two surveys. HIV Clin Trials 12: 37-47.

34. Zekeri AA, Habtemariam T, Tameru B, Ngawa D, Robnett V (2009) Conspiracy beliefs about HIVIAIDS among HIV-positive African-American patients in rural Alabama. Psychol Rep 104: 388-394.

35. Bartholow BN, Buchbinder S, Celum C, Goli V, Koblin B, et al. (2005) HIV sexual risk behavior over 36 months of follow-up in the world's first HIV vaccine efficacy trial. J Acquir Immune Defic Syndr 39: 90-101.

36. Van De Ven P, Bartholow B, Rawstorne P, Crawford J, Kippax S, et al. (2002) Scaling HIV vaccine attitudes among gay men in Sydney, Australia. AIDS Res Hum Retroviruses 18: 1333-1337.

37. Li Q, Luo F, Zhou Z, Li S, Liu Y, et al. (2010) Willingness to participate in HIV vaccine clinical trials among Chinese men who have sex with men. Vaccine 28: $4638-4643$.

38. Newman PA, Duan N, Lee SJ, Rudy E, Seiden D, et al. (2007) Willingness to participate in HIV vaccine trials: the impact of trial attributes. Prev Med 44 554-557.

39. ClinicalTrials.gov - What are clinical trial phases?

40. Kibler JL, Brisco K (2006) Evaluation of a brief questionnaire for assessing Barriers to Research Participation. Ethn Dis 16: 547-550. 
Citation: Ma M, Toni Young A, Durham M, Kibler JL, Gaul Z, et al. (2014) Predictors of Willingness of Participate in HIV Vaccine Trials among African Americans. J AIDS Clin Res 5: 361. doi:10.4172/2155-6113.1000361

Page 7 of 7

41. Westergaard RP, Beach MC, Saha S, Jacobs EA (2014) Racial/ethnic differences in trust in health care: HIV conspiracy beliefs and vaccine research participation. J Gen Intern Med 29: 140-146.

42. Bogart LM, Thorburn S (2005) Are HIVIAIDS conspiracy beliefs a barrier to
HIV prevention among African Americans? J Acquir Immune Defic Syndr 38: 213-218.

43. Kelley RT, Hannans A, Kreps GL, Johnson K (2012) The Community Liaison Program: a health education pilot program to increase minority awareness of HIV and acceptance of HIV vaccine trials. Health Educ Res 27: 746-754. 